\title{
Distribution of $\gamma$-glutamyl transpeptidase in the mouse epididymis and its response to acivicin
}

\author{
Y. P. Agrawal, T. Peura and T. Vanha-Perttula \\ Department of Anatomy, University of Kuopio, P.O. Box 6, 70211 Kuopio, Finland
}

\begin{abstract}
Summary. $\gamma$-Glutamyl transpeptidase $(\gamma-G T)$, its substrate (GSH) and hydrolytic product (L-glutamic acid) were measured biochemically in mouse reproductive tissues. The epididymal caput and seminal vesicles showed the highest specific activities of $\gamma$-GT, while GSH and L-glutamic acid were widely distributed in all tissues. Histochemically, $\gamma$-GT displayed a strong apical and supranuclear reaction and a moderate basal activity in the ductuli efferentes, a weak luminal reaction in the first, a moderate apical reaction in the second and a strong apical and supranuclear reaction in the third segment of the epididymal caput. In the epididymal corpus and cauda, the $\gamma$-GT reaction was confined to the tubular lumina but an apical reaction was also present in the cauda. The daily administration of acivicin $(12 \mathrm{mg} / \mathrm{kg}$ body weight $)$, an irreversible inhibitor of $\gamma$-GT, for 14 days resulted in a $60 \%$ suppression of the enzyme activity in the epididymal caput, while the $\gamma$-GT inhibition in the kidney was $>95 \%$. The treatment caused no change in the activity of alanyl aminopeptidase. Histochemically, the basal and supranuclear $\gamma$-GT activities in the ductuli efferentes and the third epididymal segment were suppressed, but the apical reactions were maintained. The in-vivo suppression of epididymal $\gamma$-GT activity may have implications in the control of post-testicular sperm maturation.
\end{abstract}

Kelwords: $\gamma$-glutamyl transpeptidase; acivicin; mouse; epididymis

\section{Introduction}

$\gamma$-Glutamyl transpeptidase ( $\gamma$-GT; EC 2.3.2.2) is an enzyme which removes L-glutamic acid with a $\gamma$-linkage from the $\mathrm{NH}_{2}$-terminus of peptides and proteins by its hydrolytic action or transfers it to other amino acids or peptides by its transpeptidating action (Tate \& Meister, 1981). The main physiological substrate of $\gamma$-GT in body tissues is reduced glutathione (GSH). $\gamma$-GT has been extensively studied in the kidney, where it is presumed to be involved in amino acid transport and glutathione (GSH) metabolism as a part of the $\gamma$-glutamyl cycle.

Early studies on $\gamma$-GT revealed that the epididymides of dog, mouse and rat contain high levels of the enzyme (Goldbarg et al., 1960). Later histochemical studies indicated that the epithelial border of the human and rat epididymides as well as the intraluminal spermatozoa are reactive (Glenner et al., 1962; Albert et al., 1964; Rutenburg et al., 1969; Lojda, 1975; Gossrau, 1978; Kohdaira et al., 1986). Biochemical analyses in the rat showed that the epididymis and particularly its caput contains a very high $\gamma$-GT activity (Kohdaira et al., 1986), which is bound to particles (DeLap et al., 1977). In isoelectric focussing the isoenzyme pattern of the epididymal $\gamma$-GT differed from that of the kidney and the specific activity increased during sexual maturation. It was also observed that the intraluminal activity is obviously due to a secretory enzyme, since washed spermatozoa contained low $\gamma$-GT levels.

Few attempts have been made, however, to evaluate the function of $\gamma$-GT in reproduction. Recent work indicates that the high levels of free L-glutamic acid in the mammalian epididymis 
result from the hydrolytic activity of $\gamma$-GT on GSH (Agrawal \& Vanha-Perttula, 1988b). It has also been speculated that the transpeptidating activity of $\gamma$-GT may be involved in transferring L-glutamic acid residues to acceptors on the sperm surface with a resultant increase in the negative surface charge during the epididymal transit (Agrawal \& Vanha-Perttula, 1988a). The possibility of transpeptidation to the sperm surface or formation of other bioactive $\gamma$-glutamyl compounds is a distinct possibility which has not been ruled out. $\gamma$-GT in the epididymal epithelium would be strategically well placed to influence post-testicular spermatozoa as they emerge from the ductuli efferentes. Therefore, inhibition of $\gamma$-GT or other enzymes of the $\gamma$-glutamyl cycle in the epididymal caput at a stage when spermatozoa have not yet achieved fertilizing ability might allow the development of male anti-fertility agents. We have evaluated the mouse as an experimental animal for such studies and identified the distribution of the enzyme $(\gamma-\mathrm{GT})$, substrate $(\mathrm{GSH})$ and product (Lglutamic acid) in the reproductive system. Acivicin, a specific inhibitor of $\gamma-$ GT (Gardell \& Tate, 1980), was used in an attempt to inhibit the epididymal $\gamma$-GT under in-vivo conditions with simultaneous monitoring of GSH and L-glutamic acid levels.

\section{Materials and Methods}

Adult CD2Fl mice ( $>7$ weeks of age and $2527 \mathrm{~g}$ body weight) were obtained from the Laboratory Animal Center of the University of Kuopio. Animals were fed with standard rat chow and water ad libitum. The distribution of $\gamma-\mathrm{GT}$, GSH and L-glutamic acid was analysed from mice, which were killed by cervical dislocation and bled. The reproductive organs (testis, caput and cauda epididymidis, vas deferens, coagulating glands, seminal vesicles, prostate, Cowper's glands, preputial glands) were dissected out. For the assay of GSH and L-glutamic acid, tissue pieces were weighed and to each sample $1 \mathrm{ml} 0.1 \mathrm{M}$-formic acid was added. GSH was measured fluorometrically using $o$-phthalaldehyde (Sigma Chem. Co., St Louis, MO, USA) as the reagent, while L-glutamic acid was analysed by a spectrophotometric assay (Boehringer Mannheim, Mannheim, FRG) as described by Agrawal \& Vanha-Perttula (1988b). Samples for $\gamma$-GT and alanyl aminopeptidase (AAP; EC 3.4.11.2) assays were frozen at $-20^{\circ} \mathrm{C}$, thawed and homogenised in $0.02 \mathrm{M}$-Tris- $\mathrm{HCl}$ buffer, pH 8.0. $\gamma$-Glutamyl-p-nitroanilide and alanyl- $\beta$-naphthylamide (Bachem Feinchemikalien, Bubendorf, Switzerland) were used as substrates (Agrawal \& Vanha-Perttula, 1985, 1988b). Some tissues, such as different segments of the epididymis, were collected from both sides for the assay.

Acivicin [AT-125; ( $\alpha$-S,5S)- $\alpha$-amino-3-chloro-4,5-dihydro-5-isoxazoleacetic acid] was obtained from Sigma Chemical Co. It was dissolved in $0.9 \%(\mathrm{w} / \mathrm{v}) \mathrm{NaCl}$ and aliquants were stored frozen at $-20^{\circ} \mathrm{C}$ until used. Mice were injected with $\simeq 300 \mu \mathrm{g}$ acivicin in $200 \mu \mathrm{l}$ saline $(12 \mathrm{mg} / \mathrm{kg}$ body weight) once daily subcutaneously in the back. Acivicin-injected mice were killed at 6 and 14 days of treatment about $12 \mathrm{~h}$ after the last dose. The controls consisted of age-matched uninjected mice. The animals were killed by cervical dislocation and bled. The epididymides and kidneys were collected for analyses.

For enzyme histochemistry 5 normal mice and 3 animals treated twice daily with acivicin ( $12 \mathrm{mg} / \mathrm{kg}$ body weight) for 5 days were used. The mice were killed and the epididymides were cut at $4 \mu \mathrm{m}$ with a cryostat. The histochemical localization of $\gamma$-GT was carried out according to Rutenburg et al. (1969) with $\gamma$-glutamyl-4-methoxy-2-naphthylamide (Bachem Feinchemikalien) as substrate and Fast Blue B as the diazo coupling agent in $0 \cdot 1 \mathrm{M}-\mathrm{Tris}-\mathrm{HCl}$ buffer, pH 7.2, and $20 \mathrm{~mm}$-glycyl-glycine. The controls were incubated in substrate-free reaction medium.

For statistical analyses Student's $t$ test was used.

\section{Results}

The distribution of $\gamma$-GT in mouse reproductive tissues is shown in Fig. 1(a). The epididymal caput displayed significantly $(P<0 \cdot 001)$ higher activity than any other tissue. A rather high activity was also found in the seminal vesicles. Other tissues contained very low levels of $\gamma$-GT. GSH was widely distributed in all reproductive tissues but the highest level was encountered in the vas deferens (Fig. 1b). The estimation of L-glutamic acid (Fig. 1c) in tissue homogenates showed that, although Lglutamic acid was also widely distributed in the reproductive tissues, the epididymal caput contained 4 times more than did the cauda $(P<0.01)$. These findings were very consistent in replicate experiments.

Figure 2(a) shows the percentage changes of $\gamma$-GT, GSH, L-glutamic acid and AAP from the controls $(100 \%)$ in the epididymal caput at 6 and 14 days of acivicin treatment. About $40 \%$ $(P<0.01)$ and $60 \%(P<0.001)$ suppression of $\gamma$-GT activity could be achieved at these two time 

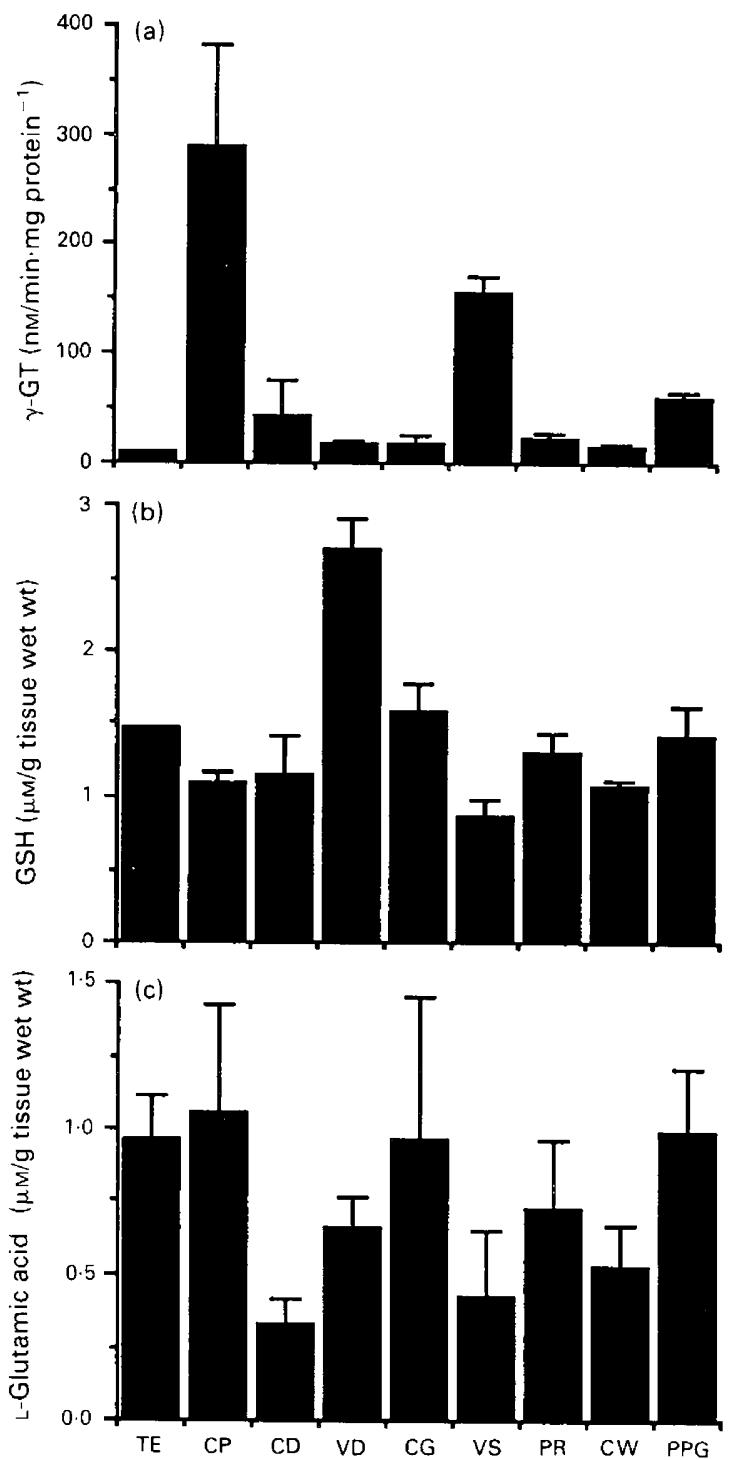

Fig. 1. The specific activity of $\gamma$-GT in the presence of Gly-Gly (20 mm) at pH 8 (a), glutathione content (b) and free L-glutamic acid content (c) in homogenates of mouse reproductive tissues. Each bar represents the mean \pm s.d. of duplicate analysis from 3 mice. The tissues studied were testis (TE), caput (CP) and cauda (CD) epididymidis, vas deferens (VD), coagulating gland (CG), seminal vesicles (VS), prostate (PR), Cowper's gland (CW) and preputial gland (PPG).

points, respectively. In contrast, GSH, L-glutamic acid and AAP levels were not statistically different from those of the controls, although L-glutamic acid showed a downward trend. Values of the kidney tissue from the same animals are shown in Fig. 2(b). A nearly complete suppression of $\gamma$-GT was observed after 14 days of treatment and GSH concentration increased markedly $(P<0.001)$, while L-glutamic acid and AAP levels did not differ from those of the controls.

The histochemical distribution of $\gamma$-GT in the epididymal caput is shown in Fig. 3(a). At the top of the section a few intensely stained ductuli efferentes were seen. They were adjoining to the epididymal caput segment 1 , which showed only a very weak reaction. An intermediate reaction 


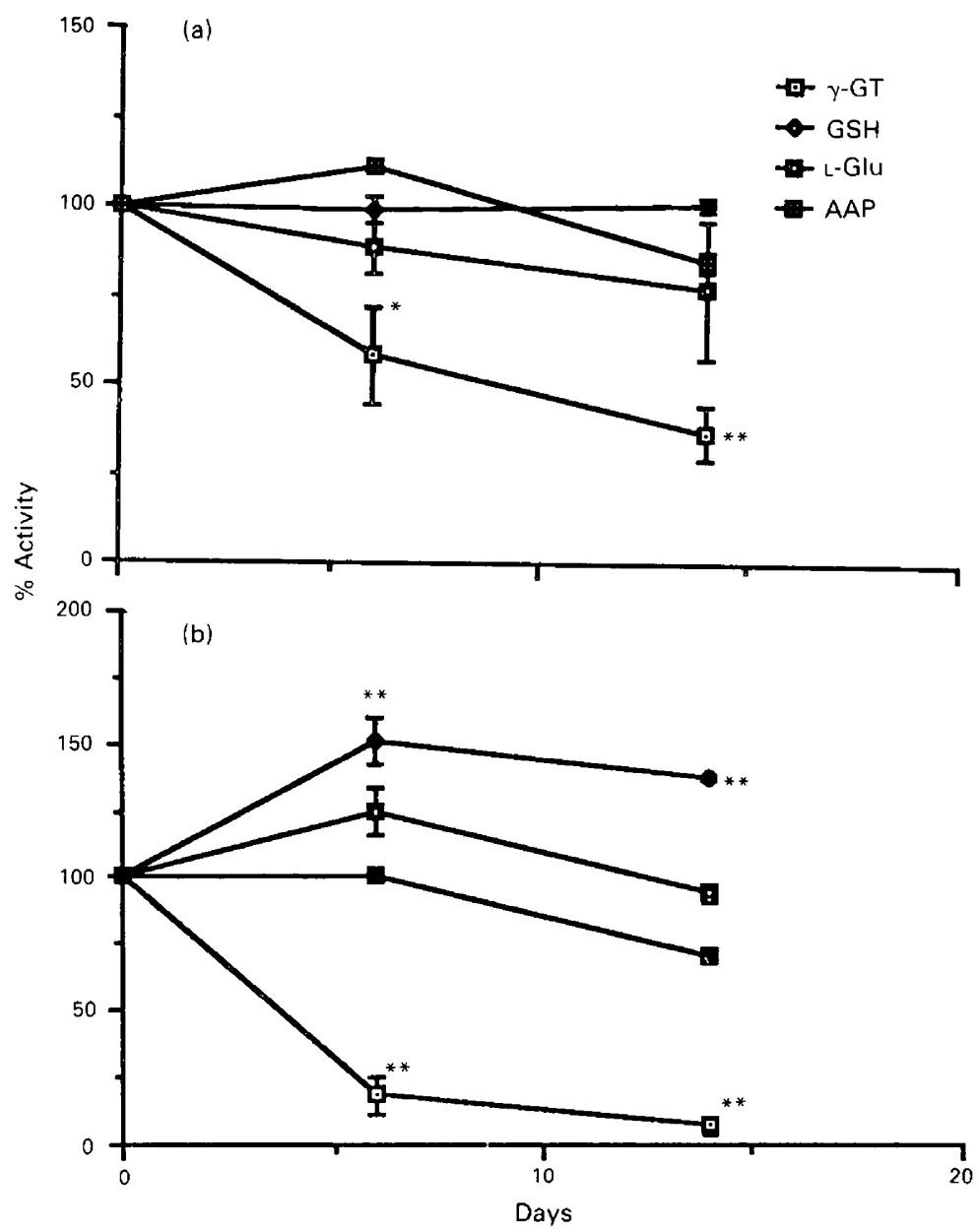

Fig. 2. Effect of acivicin (injected s.c. in the back; $12 \mathrm{mg} / \mathrm{kg}$ once daily) on $\gamma$-glutamyltranspeptidase ( $\gamma$-GT), reduced glutathione (GSH), L-glutamic acid (L-Glu) and alanyl aminopeptidase (AAP) levels in (a) the caput epididymidis and (b) the kidney of mice at 6 and 14 days of treatment. Values represent percentage changes (mean \pm s.e.m. of duplicate measurements; $\mathrm{N}=3$ ) compared to the age-matched controls $(\mathrm{N}=9)$.

was seen in the caput segment 2 , while segment 3 in the lower caput displayed a strong reaction. The weak reaction in the first segment appeared to be mainly intratubular, while the second segment displayed a moderate apical staining (Fig. 3b). At higher magnification the $\gamma$-GT reaction in the ductuli efferentes was strongest in the supranuclear (Golgi) area but apical and basal reactions could also be seen (Fig. 4a). In the third segment a very strong reaction was seen, which covered the apical and supranuclear part of the epithelial cells (Fig. 3b). In the epididymal corpus the $\gamma$-GT reaction was seen only in the tubular content, while in the cauda the epididymal epithelium again displayed a narrow apical enzyme reaction together with the intraluminal reaction (Fig. 4c).

$\gamma$-GT activity was also measured biochemically in different epididymal segments of 5 animals. Segment 1 could be clearly defined from the others by its pinkish colour. The specific activities (mean \pm s.d.) were $78 \cdot 0 \pm 35 \cdot 6,352 \cdot 6 \pm 68 \cdot 8,589 \cdot 0 \pm 23 \cdot 1,82 \cdot 2 \pm 26 \cdot 0$ and $96.9 \pm 5 \cdot 8 \mathrm{nmol} /$ min $\cdot \mathrm{mg} \mathrm{protein}^{-1}$ for caput segments $1-3$, corpus and cauda, respectively. The acivicin-treated mice showed a clear reduction in the basal reaction (Fig. 4b). Similarly, the supranuclear reaction in 

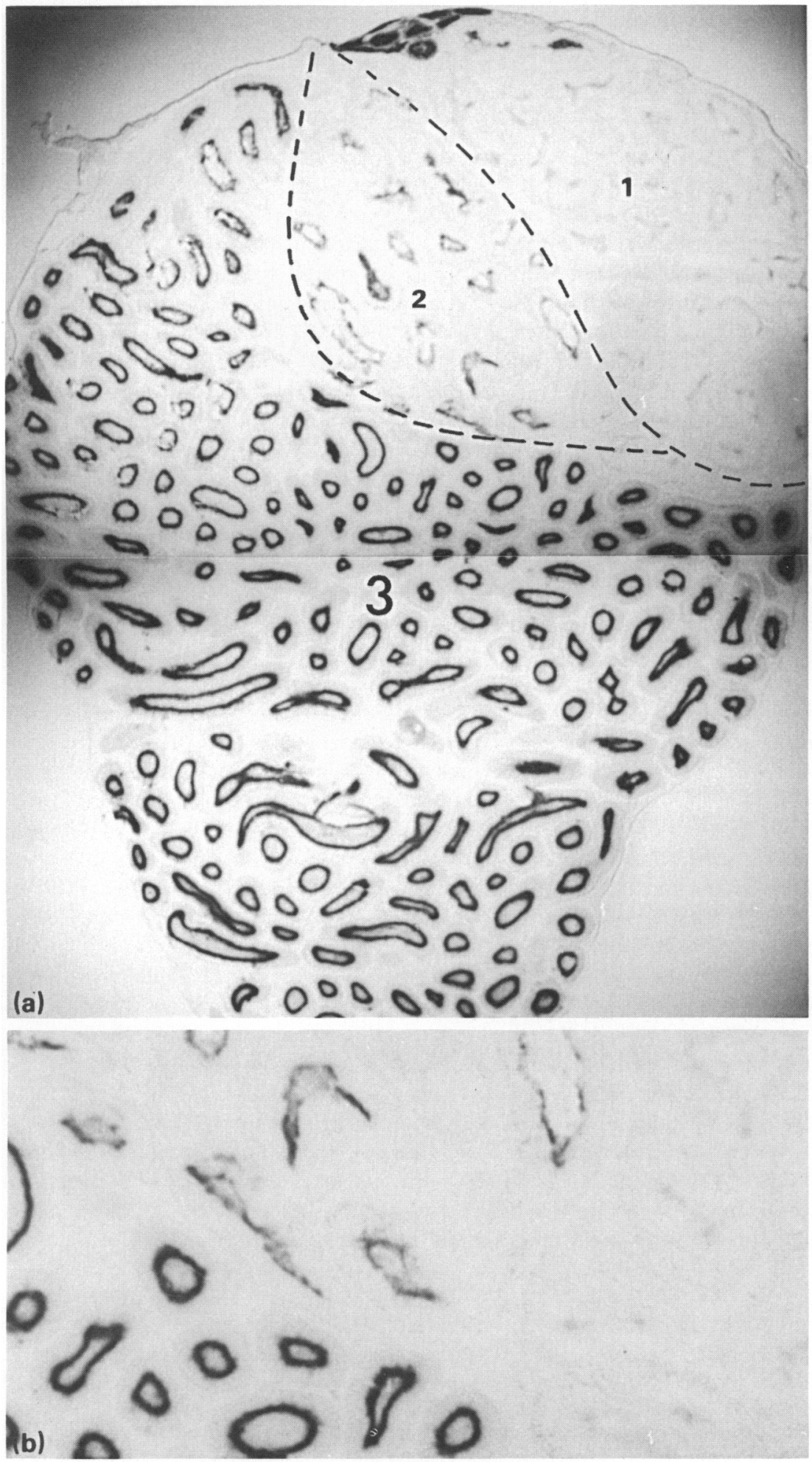
segment 3 was reduced, but a strong apical reaction still remained in segments 2 and 3 . No changes in the body weight or other side-effects were noticed in the acivicin-treated mice.

\section{Discussion}

In this study we have shown that $\gamma$-GT is strongly active in the mouse epididymal caput, while the cauda displayed much lower activity. A similar enzyme distribution has previously been described for the bull (Agrawal \& Vanha-Perttula, 1988a) and rat (Kohdaira et al., 1986; Agrawal \& Vanha-Perttula, 1988b). Histochemically, $\gamma-\mathrm{GT}$ was most marked in the epithelium of the ductuli efferentes and of a specific area (segment 3) in the mouse epididymal caput. Two other caput segments ( 1 and 2 ) displayed much lower apical reactions. The epididymal corpus showed an enzyme reaction in the luminal contents, while in the cauda an apical reaction was again present. An obvious basal activity was only found in the ductuli efferentes, which also had a supranuclear strong reaction. In segment 3 the histochemical reaction appeared to occupy an apical as well as supranuclear staining. These results indicate that the mouse epididymal epithelium is regionally specialized, although rather small morphological differences have been found (Abe et al., 1983). Since $\gamma$-GT staining could be seen in the lumen of segments below the caput, it is likely that the enzyme is mainly secreted by the caput segment 3 and becomes mixed with spermatozoa. This conclusion is supported by biochemical (DeLap et al., 1977) and histochemical (Gossrau, 1978; Matsuzawa, 1981) studies in the rat, which have also shown $\gamma$-GT activity in the lumen and bound to the sperm surface. A detailed regional distribution has not, however, been provided for this species. In the intratubular location the enzyme may carry out hydrolytic and transpeptidation reactions.

The epididymal caput was rich in GSH, the essential substrate, and L-glutamic acid, the product of the hydrolytic activity of $\gamma$-GT. Such a distribution was also observed in the bovine epididymal caput (Agrawal \& Vanha-Perttula, 1988a). Strong evidence has also been presented that $\gamma$-GT in the rat epididymis is responsible for the high L-glutamic acid concentration in the luminal fluid (Agrawal \& Vanha-Perttula, 1988b). $\gamma$-GT is the key enzyme in the $\gamma$-glutamyl cycle and GSH is an important cellular (e.g. in epididymal epithelium and spermatozoa) constituent responsible for a variety of life processes including detoxification of xenobiotics, maintenance of SH levels in proteins and protection against peroxidation damage of membranes (Tate \& Meister, 1981; Wiechetek \& Slaweta, 1987). Interference with these processes during the epididymal transit of spermatozoa could lead to impaired fertility.

In this work we used acivicin to inhibit the epididymal $\gamma$-GT under in-vivo conditions. Previously acivicin has been used to inhibit $\gamma$-GT under in-vivo conditions in the rat kidney (Scott \& Curthoys, 1987) and brain (Hill et al., 1985) and during perfusion in bile (Ballatori et al., 1988). These studies have resulted in glutathionuria and an accumulation of tissue GSH with a decrease of free L-glutamic acid levels. We were able to achieve an inhibition of $\simeq 60 \%$ for the epididymal $\gamma$-GT, whereas the renal inhibition was nearly complete. However, L-glutamic acid and GSH levels did not show any significant changes from those of the controls in the epididymis, while an increased GSH level was found in the kidney. Although a decline has been observed in urinary and biliary secretion a few hours after the drug administration, no previous data are available on longterm effects of acivicin treatment on GSH and L-glutamic acid levels. The specificity of the $\gamma-G T$

Fig. 3. A composite picture of the mouse caput epididymidis (a) showing the histochemical localization of $\gamma$-GT with $\gamma$-Glu-4-methoxy-2-naphthylamide as substrate. Attached ductuli efferentes can be seen at the top. The caput itself shows segment 1 with very faint $\gamma$-GT staining, segment 2 with moderate apical staining and segment 3 with the strongest activity. $\times 40$. An area showing segments $1-3$ (b). $\times 100$. 

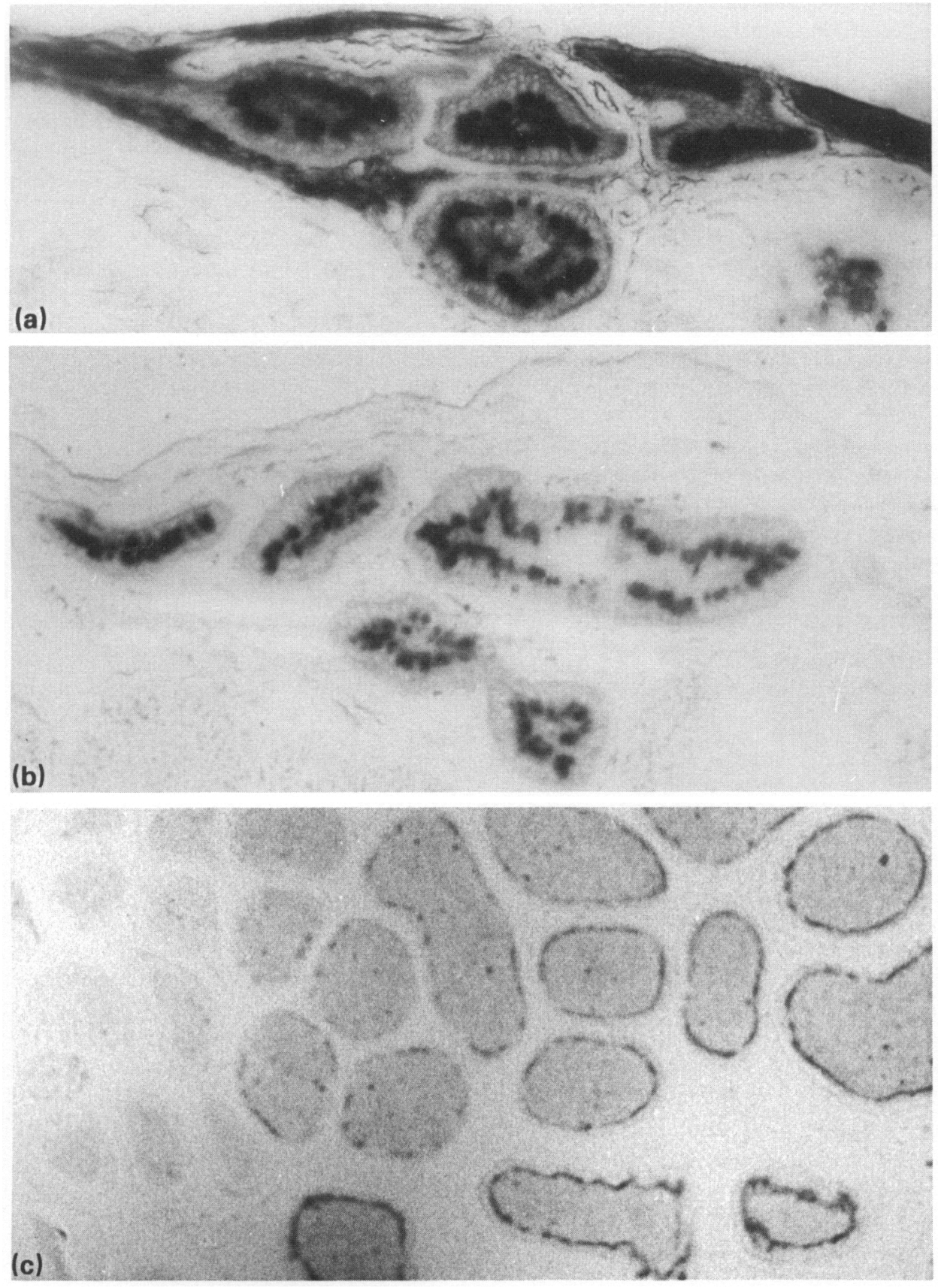

Fig. 4. Histochemical demonstration of $\gamma$-GT in (a) the ductuli efferentes of a control mouse with a strong apical and a weaker basal activity; (b) the ductuli efferentes after acivicin injections $(12 \mathrm{mg} / \mathrm{kg}$ twice a day at an interval of $8 \mathrm{~h}$ for 5 days): there is weaker apical $\gamma$-GT reaction and the basal activity has nearly disappeared; (c) the tubular contents of the epididymal corpus (at the left) and cauda (at the right): the epithelial surface of the cauda also shows an apical reaction. $\times 250$. 
suppression was confirmed by the maintenance of the AAP activity, another brush border enzyme, at a constant level during the treatment.

In interpreting our data, it is necessary to note that the epididymal GSH and L-glutamic acid values represent both the secretory and cytoplasmic forms. It is likely that the cellular pools of GSH and L-glutamic acid were either unaffected, maintained by compensatory mechanisms or, due to the special topology of $\gamma$-GT, the drug was ineffective. Our results are best explained if we consider that the catalytic site of $\gamma$-GT is on the outside of the cell membrane (Tate \& Meister, 1981). The translocation of intracellular GSH into the epididymal lumen is then necessary for the hydrolysis of GSH by $\gamma$-GT. Acivicin may, however, not readily reach the epididymal lumen, where the inhibition should take place. This statement is supported by our finding that, in the ductuli efferentes, the basal $\gamma$-GT reaction disappeared and also in epididymal segment 3 the supranuclear staining decreased after acivicin but the apical reaction remained strong. Even in kidney the basolateral $\gamma$-GT is much more sensitive to acivicin than the apical activity in the proximal convoluted tubules (Dass \& Welbourne, 1982; Spater et al., 1982). Due to glomerular filtration acivicin eventually also reaches the apical enzyme resulting in a nearly complete inhibition of the kidney $\gamma$-GT.

Previous experimental studies (McGovren et al., 1981) indicated that acivicin has a short halflife of about 30-60 min. Frequent injections are therefore required to maintain effective inhibitory blood and tissue levels. A sustained dosage of acivicin should be established to achieve a more complete and prolonged suppression of the epididymal $\gamma$-GT activity. To avoid the enzyme suppression in other tissues and organs, the drug administration should be selectively targeted to the epididymis.

This investigation received financial support from the Special Programme of Research, Development, and Research Training in Human Reproduction, World Health Organization.

\section{References}

Abe, K., Takano, H. \& Ito, T. (1983) Ultrastructure of the mouse epididymal duct with special reference to the regional differences of the principal cells. Archs Histol. Japon. 46, 51-68.

Agrawal, Y. \& Vanha-Perttula, T. (1985) Variable distribution of aminopeptidase $\mathrm{A}$ in male reproductive organs of mammals. Int. J. Androl. 8, 243-256.

Agrawal, Y. \& Vanha-Perttula, T. (1987) Effect of secretory particles in bovine seminal vesicle secretion on sperm motility and acrosome reaction. J. Reprod. Fert. 79, 409-419.

Agrawal, Y.P. \& Vanha-Perttula, T. (1988a) Glutathione, L-glutamic acid and $\gamma$-glutamyl transpeptidase in the bull reproductive tissue. Int. J. Androl. 11, $123-131$.

Agrawal, Y.P. \& Vanha-Perttula, T. (1988b) $\gamma$-Glutamy] transpeptidase, glutathione and L-glutamic acid in the rat epididymis during postnatal development. Biol. Reprod. 38, 996-1000.

Albert, Z., Orlowska, J., Orlowski, M. \& Szewczuk, A. (1964) Histochemical and biochemical investigations of gamma-glutamyltranspeptidase in the tissues of man and laboratory rodents. Acta histochem. 18, 78-89.

Ballatori, N., Jacob, R., Barrett, C. \& Boyer, J.L. (1988) Biliary catabolism of glutathione and differential reabsorption of its amino acid constituents. Am. J. Physiol. 254, G1-G7.

Dass, P.D. \& Welbourne, T.C. (1982) Effect of AT-125 on in situ renal $\gamma$-glutamyltransferase activity. FEBS Lett. 144, $21-24$.

DeLap, L.W., Tate, S.S. \& Meister, A. (1977) $\gamma$-Glutamyl transpeptidase and related enzyme activities in the reproductive system of the male rat. Life Sci. 20 , $673-680$.

Gardell, S.J. \& Tate, S.S. (1980) Affinity labeling of $\gamma$ glutamyl transpeptidase by glutamine antagonists. FEBS Lett. 122, 171-174.

Glenner, G.G., Folk, J.E. \& McMillan, P.J. (1962) Histochemical demonstration of a gamma-glutamyltranspeptidase-like activity. J. Histochem. Cytochem. 10, $481-489$.

Goldbarg, J.A., Friedman, O.R., Pineda, E.P., Smith, E.E., Chatterji, R., Stein, E. \& Rutenburg, A.M. (1960) The colorimetric determination of $\gamma$-glutamyl transpeptidase with a synthetic substrate. Archs Biochem. Biophys. 91, 61-70.

Gossrau, R. (1978) Zur Verteilung der Stereocilienenzyme im Nebenhodengang von Ratten. Histochemistry 57, $145-159$.

Hill, K.E., Von Hoff, D.D. \& Burk, R.F. (1985) Effect of inhibition of $\gamma$-glutamyltranspeptidase by AT- 125 (Acivicin) on glutathione and cysteine levels in rat brain and plasma. Invest. New Drugs 3, 3 I-34.

Kohdaira, T., Kinoshita, Y., Konno, M. \& Oshima, H. (1986) Distribution of $\gamma$-glutamyl transpeptidase in male reproductive system of rats and its age-related changes. Andrologia 18, 610-617. 
Lojda, Z. (1975) The use of hexazonium-p-rosanilin in the histochemical demonstration of peptidases. Histochemistry 44, 323-335.

Matsuzawa, T. (1981) Substrate specificity and histochemical distribution of aminopeptidases in rat testis and epididymis. Endocrinol. japon. 28, 469-475.

McGovren, J.P., Neil, G.L., Sem, P.C.C. \& Stewart, J.C. (1981) Sex- and age-related mouse toxicity and disposition of the amino acid antitumor agent, Acivicin. J. Pharmacol. exp. Ther. 216, 433-440.

Rutenburg, A.M., Kim, H., Fischbein, J.W., Wasserkrug, H.L. \& Seligman, A.M. (1969) Histochemical and ultrastructural demonstration of $\gamma$-glutamyl transpeptidase activity. J. Histochem. Cytochem. 17, $517-526$.

Scott, R.D. \& Curthoys, N.P. (1987) Renal clearance of glutathione measured in rats pretreated with inhibi- tors of glutathione metabolism. Am. J. Physiol. 252, F877-F882.

Spater, H.W., Poruchynsky, M.S., Quintana, N., Inoue, M. \& Novikoff, A.B. (1982) Immunocytochemical localization of $\gamma$-glutamyltransferase in rat kidney with protein A-horse radish peroxidase. Proc. natn. Acad. Sci. USA 79, 3547-3550.

Tate, S.S. \& Meister, A. (1981) $\gamma$-Glutamyl transpeptidase: catalytic, structural and functional aspects. Molec. cell. Biochem. 39, 357-368.

Wiechetek, M. \& Slaweta, R. (1987) The effect of exogenous glutathione on the fructolysis of thawed bull Bos bovis spermatozoa. Comp. Biochem. Physiol. 87B, $523-525$.

\section{Received 8 August 1988}

